\title{
Analysis of the Impact of New Media Era on Traditional Computer Education
}

\author{
Fei Lian \\ Section of Recruitment and Employment, Nanjing Institute of Industry Technology, Nanjing, CHINA
}

Received 12 June 2017 • Revised 22 August 2017 • Accepted 29 September 2017

\begin{abstract}
With the continuous popularization of Internet, the influence of new media permeates all fields and levels of society. The arrival of the new media era has brought great influence to the traditional computer education. On the one hand, it provides opportunities for computer teachers to improve their teaching ability and knowledge level, and on the other hand, they bring a certain impact. For computer teachers, how to seize the opportunities brought about by the new media era, and meet the challenges, has become a new topic. All computer teachers should attach great importance to the impact of the new media era, raise the level of computer teaching, and maintains a certain self-control, moral awareness and legal awareness, so that the new media can be used rationally. This paper firstly analyzes the existing traditional computer education under the new media era of the problem, and then elaborates on the positive impact and negative effects of the new media era on the traditional computer education. In addition, the regression model and the factors of negative impact of new media on traditional computer education are analyzed. Finally, it points out that: on the one hand, the computer teacher should speed up the learning of new technologies, explore new teaching methods, change teaching ideas, master the concept and basic knowledge of new media, the use of new media, and the understanding of new media environment, as well as the ethics and safety awareness of new media. On the other hand, new media literacy should be introduced into the computer class. Teachers and students should strengthen the new media literacy, and let students actively participate in activities, to maintain and improve the knowledge of computer. Only in this way can we improve the quality of computer teaching, make better use of new media for computer learning, and make the traditional computer education glowing with new vitality.
\end{abstract}

Keywords: new media era, computer education, impact

\section{INTRODUCTION}

With the continuous development of computer technology and network technology, human society has entered a new era of media. New media is a new form of media, information dissemination mainly depends on the network technology. The popularization of Internet makes the new media's influence has penetrated into the society in various fields and levels (Bao, 2016). The new media is a form of media accompanied by network technology, which is relative to the traditional media such as newspapers, radio and television ( $\mathrm{Fu}, 2017)$. The reform of computer teaching has always been a hot issue in the field of education and computer enthusiasts. With the advent of the new media era, more and more people begin to use the impact of the new media era on traditional computer education as a new research topic (Curini, Lacus, Canova, 2015).

(C) Authors. Terms and conditions of Creative Commons Attribution 4.0 International (CC BY 4.0) apply. Correspondence: Fei Lian, Section of Recruitment and Employment, Nanjing Institute of Industry Technology, Nanjing, 210023, China, +86 13851695588. 


\section{Contribution of this paper to the literature}

- Using linear regression model to analyze the correlation of each variable and the factor coefficients, and drawing the conclusions of data research;

- First of all, the traditional computer education problems are studied; secondly, according to the problems, in-depth analysis of influencing factors is carried out, and corresponding improvement strategy are given;

- Around the era of new media, traditional computer education, multi-angle narrative is performed, which has reference value.

In the new media, the traditional computer teaching methods will be greatly affected. First of all, multimedia assisted instruction has become the development trend of computer teaching, and various new teaching methods have emerged at the same time as the new media era, such as micro class teaching method (Cheng, Wang, 2015). And students' enthusiasm for computer learning is also bound up with the teaching methods of computers. The traditional teaching methods have certain advantages, but compared to the new media era, the teaching methods still have a lot of shortcomings, resulting in that the computer teaching effect is not satisfactory. In this case, the vast number of computer workers should adapt to the trend of the times, and constantly improve the ability to use new media (Huang, 2016; Juan, 2015).

The current research on the impact of the new media era on traditional computer education is mainly reflected in the following three aspects: first, the role of new media technology in traditional computer education, and the existing advantages of the new media era compared to classroom teaching form; second, the influence of new media era on self-regulated learning computer knowledge of students; third, application of new teaching methods in the emergence of new media era in computer teaching. The above research results have promoted the impact of the new media era on computer education to a great extent (Huang, et, al., 2016). However, there are few studies on the change of traditional computer education in the new media era. Therefore, changes of computer teachers based on the new media era is the focus of the study, and that the computer teachers should be teaching in the new era is pointed out; on the other hand, role change and self - positioning should be done again, to strengthen the quality of new media (Liu, 2016; Liu, 2017). Only in this way can we adapt to the impact of the new media era on traditional computer education, so as to improve the level of computer education.

\section{REVIEW OF RESEARCH STATUS}

The domestic scholars found that, at present, the traditional computer education mainly has the following problems: first, the problems existing in the computer knowledge; second, computer teachers lack sufficient preparation in the psychological level. In order to adapt to the new requirements of traditional computer education in the new media era, the traditional reform of computer teaching is imperative. This reform will be a comprehensive and thorough innovation. The content of the reform is the various aspects involved in computer teaching, with emphasis on computer knowledge, teaching methods and other aspects of innovation (Pusaksrikit, Kang, 2016). At the same time, from the aspect of computer teachers, the construction of computer teachers should take the form and the present situation of the new media era into consideration and understand the problems faced in computer education as a breakthrough and a foothold. First of all, from the aspect of computer teachers, there are many computer teachers who stick to the traditional methods of computer teaching and don't want to change it. The teaching philosophy needs to be improved (Patchen, Smithenry, 2015). Although the reform of the traditional teaching of the computer work has been ongoing, there are still a lot of computer teacher understanding of computer teaching reform is not in place, many domestic scholars believe that such reform is specious writing which cannot solve the deeper problems, therefore, it also need to attract enough attention in the mind (Rubera et al. 2016). Some computer teachers do not pay attention to conform to the current era of new media, still follow the traditional teaching method of computer teaching, for example, network teaching cannot be effectively used, some teachers even never use new media teaching methods in computer teaching, leading to the fact of that the teaching effect of traditional classroom is serious stereotype and cannot effectively mobilize the students' activities (Rehm et al., 2015). Although some teachers have used multimedia teaching means to do the teaching of computer, the 
range is very limited; And some only use simple music or video teaching, new teaching methods do not give full play to the role of new media. At the same time, many foreign scholars believe that many computer teachers need to change their roles. In the traditional computer teaching mode, teachers act as the role of a knowledge initiator. In this teaching mode, the computer teacher is the source of all computer knowledge for students, and also the judge of the accuracy of all computer knowledge. They play a leading role in the classroom. Computer teachers grow up in the traditional teaching mode, so in the era of new media, it is often difficult to integrate their role positioning with the new media era, which makes computer teachers' knowledge level to determine the quality of teaching. If the teacher's teaching level is higher, then his computer teaching effect is higher and vice versa (Zhong, et, al., 2016).

\section{METHODS}

\section{The Influence of New Media Era on Traditional Computer Education}

The positive influence of the new media era on traditional computer education. The rapid development of new media has profoundly changed the traditional mode of computer teaching and the atmosphere of computer teaching class. In the course of teaching, teachers can keep abreast of the progress of teaching, change teaching means, and control the progress of teaching according to each student's learning situation (Zhao, 2016). For example, in the computer teaching methods, teachers can use WeChat, QQ group, send the focus of the knowledge to students' mobile phone, let students learn targeted. By using micro-blog, WeChat and QQ group, teachers can carry out real-time communication with students, so that when students encounter difficult problems, they can solved them in time; the teacher can also push computer knowledge to every student's mobile phone through the creation of WeChat public number, and let students expand their knowledge. In short, as long as we make full use of the new teaching methods in the new media era, we can effectively improve the quality of computer teaching and improve students' interest in learning computers.

The negative influence of the new media era on traditional computer education. The new media in computer teaching also has a negative side, first of all, in the computer classroom teaching, many students will play with mobile phones, tablet computers and so on. The teacher is in the class, but students will secretly use mobile phone or tablet computer to play games, Internet, chat and so on (Zhu et al., 2017). The learning process of the computer need to concentrate, if students wander in the study, it is difficult to guarantee the computer learning effect; secondly, after class, the teacher arranges some tasks, students will depend too much on the network, it will make a lot of knowledge is not strong, even there will be watching forget, which reduces the computer learning effect; thirdly, many students rely too heavily on the use of electronic products and electronic products, play games, chat, Internet and so on, it will be a long time with Internet addiction.

\section{The Negative Influence Factors of New Media on Traditional Computer Education}

To some extent, the negative effects of the new media era on traditional computing education are due to the lack of education aimed at new media literacy. The lack of new media literacy in traditional computer education has led to the lack of new media literacy among computer majors. To maintain a certain self-control, moral awareness and legal awareness are the key to a person's rational use of new media.

In this study, multiple linear regression model is applied to analyze the negative impact of new media on traditional computer education:

$$
y_{i}=\beta+\alpha_{i} x_{i}
$$

The difference between the estimate and the actual value is expressed as residuals, and the exact formula is as follows:

$$
\hat{u}_{i}=\hat{y}_{i}-\beta-\alpha_{i} x_{i}
$$


Table 1. Coefficient of correlation of variables

\begin{tabular}{ccccc}
\hline $\boldsymbol{\gamma}$ & $\boldsymbol{x}_{\mathbf{1}}$ & $\boldsymbol{x}_{\mathbf{2}}$ & $\boldsymbol{x}_{\mathbf{3}}$ & $\boldsymbol{y}$ \\
\hline$x_{1}$ & 1 & 0.2351 & 0.4354 & 0.4613 \\
\hline$x_{2}$ & 1 & 0.1450 & 0.4619 \\
\hline$x_{3}$ & & 1 & 0.8465 \\
\hline$y$ & & & 1 & 1 \\
\hline
\end{tabular}

Table 2. Negative impact of new media on traditional computer education

\begin{tabular}{ccccc}
\hline \multicolumn{5}{c}{ Dependent Variable: $\mathbf{Y}$} \\
\hline Variable & Coefficient & Sncluded observations: 500 & Prob. \\
\hline$C$ & -102.4561 & 0.7032 & 5.5803 & 0.0010 \\
\hline$x_{1}$ & 2.4356 & 0.5658 & 6.4381 & 0.0484 \\
\hline$x_{2}$ & 12.2023 & 0.5475 & 1.5680 & 0.0137 \\
\hline$x_{3}$ & 9.9552 & 0.0676 & 2.5682 & 0.0547 \\
\hline
\end{tabular}

The regression coefficients of the model are calculated as follows:

$$
R S S=\sum_{i=1}^{N} \hat{u_{i}^{2}}=\sum_{i=1}^{N}\left(y_{i}-\beta-\alpha_{i} x_{i}\right)^{2}
$$

Based on this model, this research chooses three indexes to construct the negative impact of new media on traditional computer education factors, which reflect the students' understanding of new media. Where, $x_{1}$ reflects the students' understanding of new media, $x_{2}$ reflects school computer education, and $x_{3}$ reflects the quality of computer teachers. In this paper, the correlation coefficient between variables is calculated by correlation analysis, and the formula is as follows:

$$
\gamma=\frac{L_{i j}}{\sqrt{L_{i i}} \sqrt{L_{j j}}}
$$

In formula (4), $L_{i j}$ is the sum of squares of discrete differences between variables. The correlation coefficients between the variables obtained are shown in Table 1.

According to the coefficient of correlation between variables in Table 1, the regression coefficients of multiple regression equations are calculated:

$$
\hat{y}=512-24 x_{1}+79 x_{2}+10 x_{3}-72 x_{4}+8 x_{5}
$$

According to equation (5), it can be calculated the comprehensive score of negative effects factors of new media on traditional computer education. Taking into account the needs to handle large amounts of data in this study, the comprehensive score of negative influence factors in traditional computer education is made rounding, so as to do computer simulation regression.

According to the above formula, the results shown in Table 2 can be obtained.

As can be seen from Table 2, the regression items have basically passed the significant level test of 5\%, indicating that the regression results are high in reliability as a whole. The greater the regression coefficient of regression variables on the dependent variables is, the greater the impact is. It can be seen that the negative impact of new media on traditional computer education is large, the estimated value, the actual value and the residuals of the dependent variable are as shown in Figure 1.

From the research results we can see that our traditional computer education in new media literacy is still at a low level. By enhancing students' understanding of new media, school computer education and strengthening new media contacts of computer teachers, it has played a significant role in improving the quality of students' new media. 


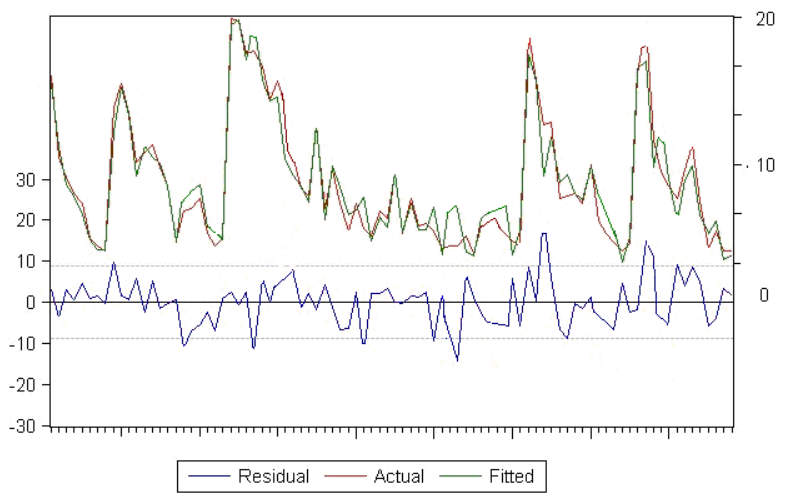

Figure 1. Sketch map of actual value, estimated value and residual of the dependent variable

\section{RESULTS}

\section{The Reasons for the Negative Impact of New Media on Traditional Computer Education}

At present, computer science major in most schools of China has established the campus network or LAN, and the computer network teaching is basically realized, however, school education is mainly to improve their computer skills, while ignoring the new media literacy education of students, because students lack of new media literacy, which cannot correctly use new media. Some school campus network cannot play its due role, it is just simply used to transfer files, do computerized office, and search information on Internet, which lacks of computer knowledge, so it is difficult to attract more students, and unable to guide students to improve the quality of new media. Therefore, students have a lot of blindness in the use of new media, and cannot accurately locate new media, resulting in students' wrong understanding of new media, and therefore using the new media incorrectly.

Secondly, as the computer teachers themselves, their behavior will have a profound impact on students, many school computer teachers usually have very little contact with new media, do not know how to use new media, and do not innovate computer teaching methods through the new media. For the students' confusion and doubt in the new media era, many computer teachers are not able to solve them accurately. Some computer teachers will have a negative impact on students, and students are unable to be correctly guided in the use of new media.

\section{The Countermeasures for the Negative Impact of New Media on Traditional Computer Education}

According to the current development of new media, the computer major of each school should gradually improve the school rules and discipline, especially strict the classroom discipline in computer teaching, such as in the computer class or the examination, students are not allowed to carry mobile phone. In students' computer students' life, strict restrictions should be placed on the time of students contacting new media, so that both wired and wireless networks can be effectively controlled. In the process of using new media, teachers should take full control of classroom discipline, communicate with students and make use of new media to stimulate students' initiative and enthusiasm in learning computers. Computer teachers should also continue to explore new media under the new teaching methods, and change the passive to active. New media is as a new channel for students to acquire knowledge.

In the computer class, if the students are found deserted, the teacher should correct and remind in time, and make reasonable punishment when necessary, so as to keep the students' attention and interest in learning. In spare time, it should make full use of the new media to set up a learning platform, such as micro-blog, WeChat or QQ group, and held some computer activities, which should be some ideas to attract students attention, and let students actively participate in activities, to maintain and improve the knowledge of computer in the interest. 
Teachers should strive to do the following in the new media era: the first is to understand the new changes of computer education under the new media environment, and comprehensively grasp the characteristics of Computer Science in new media; the second is to understand the development trend of new media, grasp the latest development results, for better servicing computer education; the third is to explore the combination of new media and computer education, continue to explore the appropriate countermeasures, actively use the advantages of new media, and constantly improve the quality of computer education.

\section{DISCUSSION}

The traditional computer education in China lacks the content of new media literacy. At present, the important content of computer education in China is the courses of computer basic knowledge and knowledge of the network, so the ideological content of new media is very weak, which makes the computer course has been stuck in the computer basic education and skills and unable to meet the requirements of the new media era. Most schools offer new media literacy courses only in the media profession, while there is no new media literacy in the computer profession. The characteristics of China's traditional examination oriented education determines the students too dependent on school education, so it is difficult to rely on their own initiative to strengthen new media literacy, and the lack of schools in this area also causes students to face the confusion in new media era.

Over time, the impact of the new media on the traditional computer education is more and more big, to this end, we must continue to explore corresponding countermeasures, so as to reduce the negative influence of the new media era. The new media literacy education should be introduced into traditional computer teaching. New media literacy education should include the following contents: mastering the new media concept, basic knowledge and the application of new media, understanding of the new media environment, and grasping the moral quality and safety awareness of the new media master etc.. Only by improving the new media literacy of teachers and students can we make better use of new media for computer learning.

\section{CONCLUSION}

The continuous development of new media has a great influence on the traditional computer education, both positive and negative effects. As the teacher and student are in new media era, it is necessary to improve the knowledge of new media, but also has the new media literacy. Only by constantly innovating the teaching methods of computer and giving full play to the role of new media, can we adapt to the development requirements of the new media era and bring new vitality to the traditional computer education.

\section{REFERENCES}

Bao, W. D. (2016). Exploration of case teaching method based on petroleum specialty. Heilongjiang Researches on Higher Education, 3(7), 168-170.

Cheng, M. Y., \& Wang, L. (2015). The Mediating Effect of Ethical Climate on the Relationship between Paternalistic Leadership and Team Identification: A Team-Level Analysis in the Chinese Context. Journal of Business Ethics, 129(3), 639-654.

Curini, L., Lacus, S., \& Canova, L. (2015). Measuring Idiosyncratic Happiness through the Analysis of Twitter: An Application to the Italian Case. Social Indicators Research, 121(2), 525-542.

Fu, R. X. (2017). Study on the evaluation of college students' integrity index. Computer simulation, 34(6), 197-199.

Huang, X. X. (2016). Rebuild professional quality education with Internet thinking. Chinese Vocational and Technical Education, 6(4), 80-83.

Huang, Y., Yang, C.G., Baek, H., Lee, S.-G. (2016). Revisiting media selection in the digital era: adoption and usage. Service Business, 10(1), 239-260.

Juan, M. C. (2015). The effects of computer-based games and collaboration in large groups vs. collaboration in pairs or traditional methods. Computers $\mathcal{E}$ Education, 87(C), 42-54.

Liu, J. (2017). Research on the practice of computer professional teachers in the background of "Internet plus". Chinese Vocational and Technical Education, 7(7), 82-87. 
Liu, S. (2016). A new model of flipped classroom teaching in mobile new media era is analyzed. Heilongjiang Researches on Higher Education, 13(7), 171-173.

Patchen, T., \& Smithenry, D.W. (2015). More than Just Chemistry: The Impact of a Collaborative Participant Structure on Student Perceptions of Science. Research in Science Education, 45(1), 75-100.

Pusaksrikit, T., \& Kang, J. (2016). The impact of self-construal and ethnicity on self-gifting behaviors. Journal of Consumer Psychology, 26(4), 524-534.

Rehm, M., Gijselaers, W., \& Segers, M. (2015). The impact of hierarchical positions on communities of learning. International Journal of Computer-Supported Collaborative Learning, 10(2), 117-138.

Rubera, G., Chandrasekaran, D., \& Ordanini, A. (2016). Open innovation, product portfolio innovativeness and firm performance: the dual role of new product development capabilities. Journal of the Academy of Marketing Science, 44(2), 166-184.

Zhao, M. Q. (2016). The integration design practice of "computer network foundation". Chinese Vocational and Technical Education, 4(20), 75-77.

Zhong, Z. X., Chai. M. M., \& Cheng, X. S. (2016). The design and thinking of flipped classroom in computer classes of Tibetan vocational college. Chinese Vocational and Technical Education, 4(b03), 149-152.

Zhu, J. H., Cui, Y., \& Zhu, S. Q. (2017). College students' network new media reproductive health education effect evaluation. Chinese Journal of School Health, 38(2), 258-260.

\section{http://www.ejmste.com}

